\title{
Non-coding RNAs, the Trojan horse in two-way communication between tumor and stroma in colorectal and hepatocellular carcinoma
}

\author{
Cristina- Sorina Cătană ${ }^{1}$, Martin Pichler ${ }^{2}$, Gianluigi Giannelli ${ }^{3}$, Robert M. Mader ${ }^{4}$ \\ and Ioana Berindan-Neagoe ${ }^{5,6,7}$ \\ ${ }^{1}$ Department of Medical Biochemistry, "Iuliu Haţieganu" University of Medicine and Pharmacy, Cluj-Napoca, Romania \\ 2 Department of Internal Medicine, Division of Oncology, Medical University of Graz, Graz, Austria \\ ${ }^{3}$ Department of Internal Medicine, Immunology and Infectious Diseases, Section of Internal Medicine, University of Bari \\ Medical School, Bari, Italy \\ ${ }^{4}$ Department of Medicine I, Comprehensive Cancer Center of the Medical University of Vienna, Vienna, Austria \\ ${ }^{5}$ Research Center for Functional Genomics, Biomedicine and Translational Medicine, Institute of Doctoral Studies, "Iuliu \\ Haţieganu" University of Medicine and Pharmacy, Cluj-Napoca, Romania \\ ${ }^{6}$ Department of Experimental Pathology, "Ion Chiricuta" Institute of Oncology, Cluj-Napoca, Romania \\ ${ }^{7}$ Medfuture Research Center for Advanced Medicine, Cluj-Napoca, Romania \\ Correspondence to: loana Berindan-Neagoe, email: ioana.neagoe@umfcluj.ro \\ Keywords: tumor microenvironment, microRNA, long non-coding RNA, CRC, HCC \\ Received: November 15, $2016 \quad$ Accepted: January 24, $2017 \quad$ Published: February 25, 2017
}

Copyright: Cătană et al. This is an open-access article distributed under the terms of the Creative Commons Attribution License (CC-BY), which permits unrestricted use, distribution, and reproduction in any medium, provided the original author and source are credited.

\section{ABSTRACT}

In a continuous and mutual exchange of information, cancer cells are invariably exposed to microenvironment transformation. This continuous alteration of the genetic, molecular and cellular peritumoral stroma background has become as critical as the management of primary tumor progression events in cancer cells. The communication between stroma and tumor cells within the extracellular matrix is one of the triggers in colon and liver carcinogenesis. All non- codingRNAs including long non-coding RNAs, microRNAs and ultraconserved genes play a critical role in almost all cancers and are responsible for the modulation of the tumor microenvironment in several malignant processes such as initiation, progression and dissemination. This review details the involvement of non codingRNAs in the evolution of human colorectal carcinoma and hepatocellular carcinoma in relationship with the microenvironment. Recent research has shown that a considerable number of dysregulated non- codingRNAs could be valuable diagnostic and prognostic biomarkers in cancer. Therefore, more in-depth knowledge of the role non- codingRNAs play in stroma-tumor communication and of the complex regulatory mechanisms between ultraconserved genes and microRNAs supports the validation of future effective therapeutic targets in patients suffering from hepatocellular and colorectal carcinoma, two distinctive entities which share quite a lot common non-coding RNAs.

\section{INTRODUCTION}

Non-coding RNAs (ncRNAs) are a heterogeneous class of transcribed RNA molecules from non-(protein)coding regions, which lack an open reading frame and consequently have no apparent protein-coding ability. Based on the size of the functional RNA molecule, regulatory ncRNAs are classified analytically as long
ncRNAs (lncRNAs; between $200 \mathrm{nt}$ and > $100 \mathrm{~kb}$ ), which are relatively less well-described, and small ncRNAs (sncRNAs; $18-200 \mathrm{nt}$ ) [1, 2].

In recent years, the study and understanding of the tumor microenvironment has become as important as the modulation of cancer cell progression itself [3]. Colorectal carcinoma (CRC) and hepatocellular carcinoma (HCC) represent two cancer types highly refractory to therapy. 
$\mathrm{HCC}$ is the third leading cause of cancer- related death worldwide whereas the overall survival of CRC patients seems not to be substantially improved in the last decade $[4,5]$.

Although advancements have been made with regard to available therapy benefits, there are only modest improvements in the survival rates of CRC and HCC patients due to the lack of early detection and excellent prognostic indicators [2].

Molecules secreted by $\mathrm{HCC}$, the most frequent liver tumor type, lead to the activation of hepatic stellate cells (HSCs) that remodel peritumoral stroma and the composition of the extracellular matrix (ECM) [6]. The mutual and symbiotic interconnections between anabolic CRC cells and highly abundant catabolic stromal fibroblasts or cancer- associated fibroblast (CAFs) favor the development of tumors and metastases [7]. Moreover, substantial studies recognize HSCs as the main matrixproducing cells in liver fibrosis [8].

In addition, the communication between stroma and tumor cells within the ECM opens the way to carcinogenesis in the liver and colon. Besides the modulation of HSCs in ECM turnover, activated stellate cells are an important determinant of hepatic proinflammatory cytokines such as transforming growth factor- beta (TGF- $\beta$ ), platelet-derived growth factor (PDGF), hepatocyte growth factor (HGF), connective tissue growth factor (CTGF), fibroblast growth factor (FGF) and vascular endothelial growth factor (VEGF). They also recruit immunoinflammatory cells, monoand polimorphonuclear leukocytes which, in their turn, produce certain chemokines including $\mathrm{C}-\mathrm{C}$ chemokine receptor type (CCR5), Regulated on Activation Normal $\mathrm{T}$ Cell Expressed and Secreted (RANTES), monocyte chemotactic protein 1 (MCP-1) and CC chemokine ligand 21 (CCL21) [6].

Moreover, targeting the microenvironment containing CAFs, endothelial cells, adipocytes, immune cells and cancer stem cells (CSC), particularly the crosstalk between tumor cells and stromal cells, has emerged as an encouraging cancer therapeutic approach (CAFs derived from both stromal/ mesenchymal cells and local fibroblast). This strategy would be relevant for both HCC and CRC, which frequently develop in a setting of chronic inflammatory process and microenvironment redesign, especially associated with hepatic fibrosis to which HSC and CAFs greatly contribute [9, 10, 11] (Figure 1).

Thereby, the HSC "metamorphosis" represents a key cell-reprogramming event that favors tumor progression. Additionally, the amount of activated HSCs from the tumorigenic HCC environment after surgical resection could predict early recurrence and poor clinical outcome in HCC patients. The angiogenin secreted by $\mathrm{HCC}$ cells binds directly to the promoter region of DNA, thus inducing the biogenesis of angiogenic factors such as VEGF and FGF-2, which are important in cell growth and tumor proliferation. Consequently, targeting the angiogenin signaling pathway with small-molecule inhibitors such as non- coding RNAs could be required to cancel the activating capacity of HSCs and thus control HCC progression [6, 12].

Lately it has become obvious that the dialogue between stroma and tumor cells is not simply composed of cell-matrix adhesion and signaling secreted proteins. Lipid membrane bound exosomes are recognized vesicular transporters secreted from both stromal and cancer cells that control the gene expression of neighboring cells. Generally, exosomes deliver their protein and RNA load and adjust gene expression in the recipient cells. Among their cargo miRNAs emerge as important players because they are almost stable compared to proteins and mRNA. Furthermore, they accumulate to a level that can generate a durable biological effect [7]. Thus, non-coding RNAs could represent important signaling mediators, likely superior to secreted proteins such as growth factors and chemokines.

CRC and HCC share common non-coding RNAs despite major differences between them in terms of clinical aspects and treatment. These non-coding RNAs are emerging as key potential biomarkers in both types of cancer thus providing us with a new perspective to our understanding of their molecular mechanisms, at the same time also providing new therapeutic opportunities. This review presents a genomic standpoint on the alterations of non-coding RNAs in liver and CRC tumor microenvironment. It also highlights the significance of the interaction between tumor and stromal cells through the activation of HSCs / CAFs, which have a key role in tumor initiation and development.

\section{DYSREGULATION OF CERTAIN KEY LONG NON-CODING RNAS (LNCRNAS) AND MIRNAS INVOLVED IN HCC/ CRC}

The lncRNAs family contains multiple classes of RNAs, which are nuclear RNAs greater than 200 nucleotides involved in the regulation of cellular processes such as apoptosis, proliferation and metastases [13] (Figure 2, 3).

Conversely, microRNAs are an abundant class of endogenous small RNA molecules, 20-25 nucleotides in length, which act as oncogenes and tumor suppressors and thus have crucial roles in carcinogenesis [14, 15]. Similar to miRNAs, the dysregulation of lncRNAs is associated with human colorectal and hepatocellular cancers and defines their phenotypes. Therefore, lncRNAs and microRNAs (miRNAs), which are long and small non-coding RNA molecules involved in the posttranscriptional regulation of gene expression and in target gene translation, may become non-invasive diagnostic biomarkers and powerful tools in cancer prevention and treatment $[16,17]$. 
miRNAs commonly involved in $\mathrm{HCC}$ and $\mathrm{CRC}$

Recent research revealed two key roles of miRNAs in the dynamics of tumor microenvironment: in tumor cells, they modify the peritumoral stroma and the composition of the ECM through their own mechanisms while in neighboring cells, they imprint cancer hallmark (Figure 2). Molecular modulators from the tumor microenvironment represent the most promising core targets of miRNAs (Table 1). These miRNAs suppress the expression of multiple genes involved in tumor- stromal interactions, immune invasion and tumor angiogenesis $[18,19,20]$ (Figure 1).

Previous studies indicated that miR-34a inhibits tumor growth, miR-21 promotes apoptosis resistance of tumor cells proliferation while the miR-200 family is strongly associated with the epithelial- mesenchymal transition (EMT) [18, 19]. In human and murine HCC and CRC experimental models, extracellular vesicles (EVs) generated by metastatic breast cancer transferred miR-200 to non-metastatic cells, thus modifying gene expression programs and promoting metastasis [21] (Figure 1,2).
miRNA- 26a is a new HCC and CRC angiogenesis suppressor and a possible therapeutic target influencing the hepatocyte growth factor (HGF) - cMet pathway. It also inhibits the expression of the vascular endothelial growth factor A (VEGFA) in cancer cells. Moreover, the miR26 down-regulation increases the angiogenic potential of these types of cancers. HGF was identified as a target of miR-26a and its activation antagonizes the effects induced by the up-regulation of miR-26a [22].

Therefore, miR-26a partially exerted its antiangiogenesis effect by blocking the HGF-receptor (cMet) and its signaling pathway, thus consequently suppressing VEGFA production in HCC cells and modifying vascular endothelial growth factor receptor 2 (VEGFR2)-signaling in endothelial cells. In conclusion, HCC patients with low hepatocyte growth factor (HGF), low VEGFA, high miR26 a levels or low microvessel density in tumor cells have a better prognosis with longer overall survival and time to recurrence. In multivariate analysis, it was demonstrated that miR-26a, alone or in combination with HGF, is an independent prognostic indicator for time to recurrence and overall survival in HCC patients [22] (Figure 1).

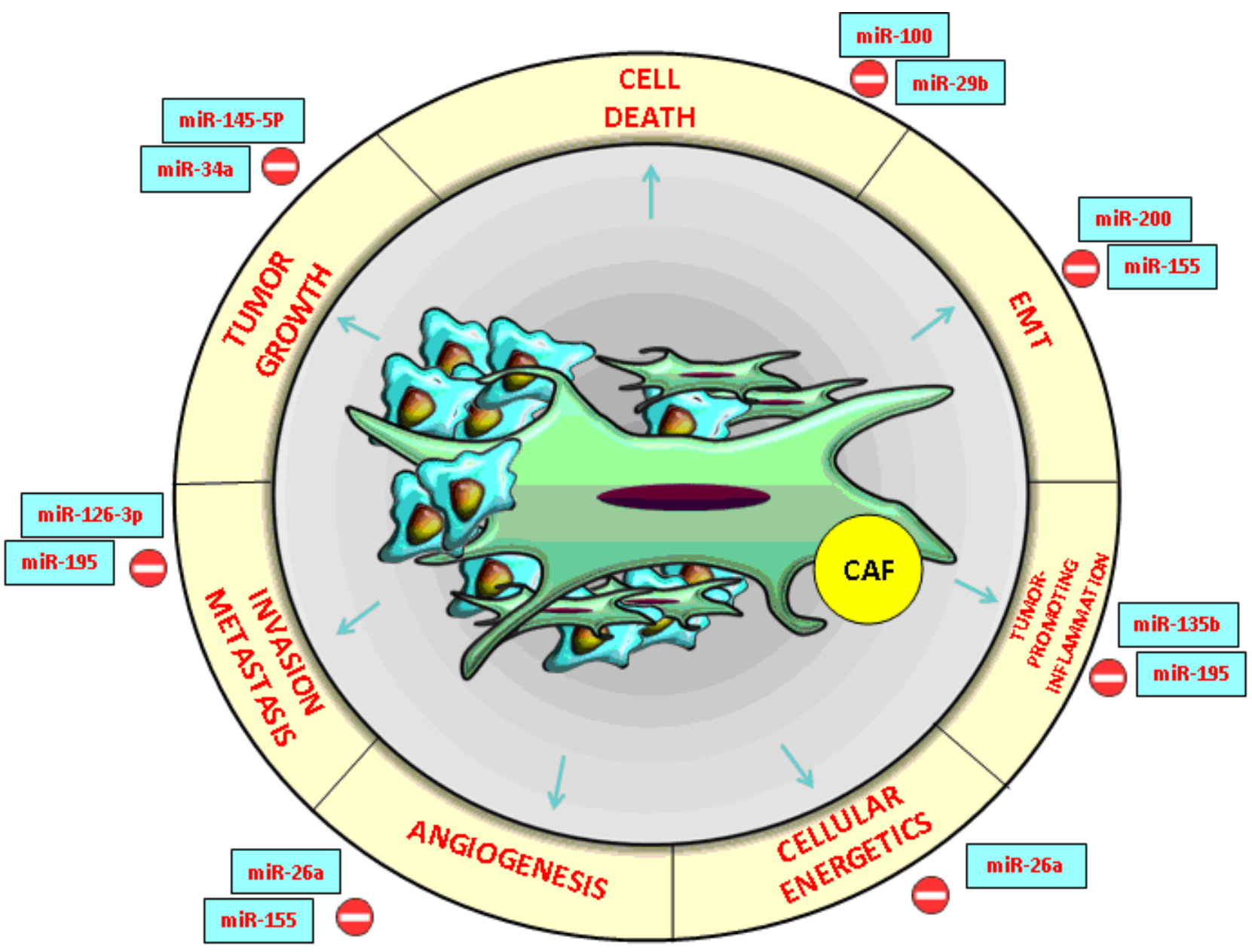

Figure 1: CRC and HCC- associated microRNAs with an essential impact on the functions of cancer- associated fibroblasts (CAFs) in the tumor microenvironment. 
miR-26a also decreases the glucose metabolism of CRC cells by direct targeting of the pyruvate dehydrogenase protein $\mathrm{X}$ component (PDHX), which blocks the conversion of pyruvate to acetyl coenzyme $\mathrm{A}$ in the Krebs cycle. The overexpression of miR-26a in tumor cells strongly improved the accumulation of pyruvate and reduced the production of acetyl coenzyme A. At the same time, the inhibition of miR-26a expression developed opposite biological effects [23].

Another promising HCC biomarker with a considerable therapeutic potential is inflamma-miR-195, which suppresses HCC angiogenesis and metastasis if overexpressed in tumor tissues. Both loss-of-function and gain-of-function research of in vitro models showed that miR-195 not only suppresses the ability of HCC cells to develop the migration and capillary formation of endothelial cells but also directly decrease the ability of HCC cells to migrate and invade the ECM gel [24].

The down-regulation of miR-195 elevated CARMA3 protein expression, whereas miR-195 upregulation abolished the Caspase recruitment domain (CARMA3 also known as CARD10) protein expression in CRC cells through NF-kB activity. Research based on mouse models indicated that induced expression of miR195 dramatically reduced tumor microvessel densities and inhibited both pulmonary and intrahepatic metastasis.
Thereafter, miR-195 directly decreases the expression of the proangiogenic VEGF and the prometastatic factors VAV2 and CDC42 from the Rho-family GTPases, which activates cellular actin dynamics in many cellular functions [24, 25] (Figure1). In addition, the restoration of miR-126-3p expression could be another example of an efficient strategy in HCC treatment, by suppressing angiogenesis and tumor metastasis through low density lipoprotein receptor-related protein 6 (LRP6) ) and Phosphoinositide-3-Kinase, Regulatory Subunit 2 (PIK3R2) specific targets. Recent research has suggested that the core target genes of miR-126 associated with anti-metastatic activity and tumor-endothelial interactions include a set of eight genes such as c-Mer tyrosine kinase receptor (MERTK), insulin-like growth factor binding protein 2 (IGFBP2) and encoding phosphatidylinositol transfer protein, cytoplasmic 1 (PITPNC1) [26]. Notably, the miR-126 expression decreased in metastatic CRC lines and, by targeting multiple signaling pathways, it could represent a potential biomarker for CRC liver metastasis [27].

In mouse models of hepatocarcinogenesis, the role of miR-122 loss was confirmed, its expression being decreased especially in non-viral HCCs. This miR is also down-regulated in CRC. Complete conservation of mature miR-122 in all vertebrates reflects its great potential in

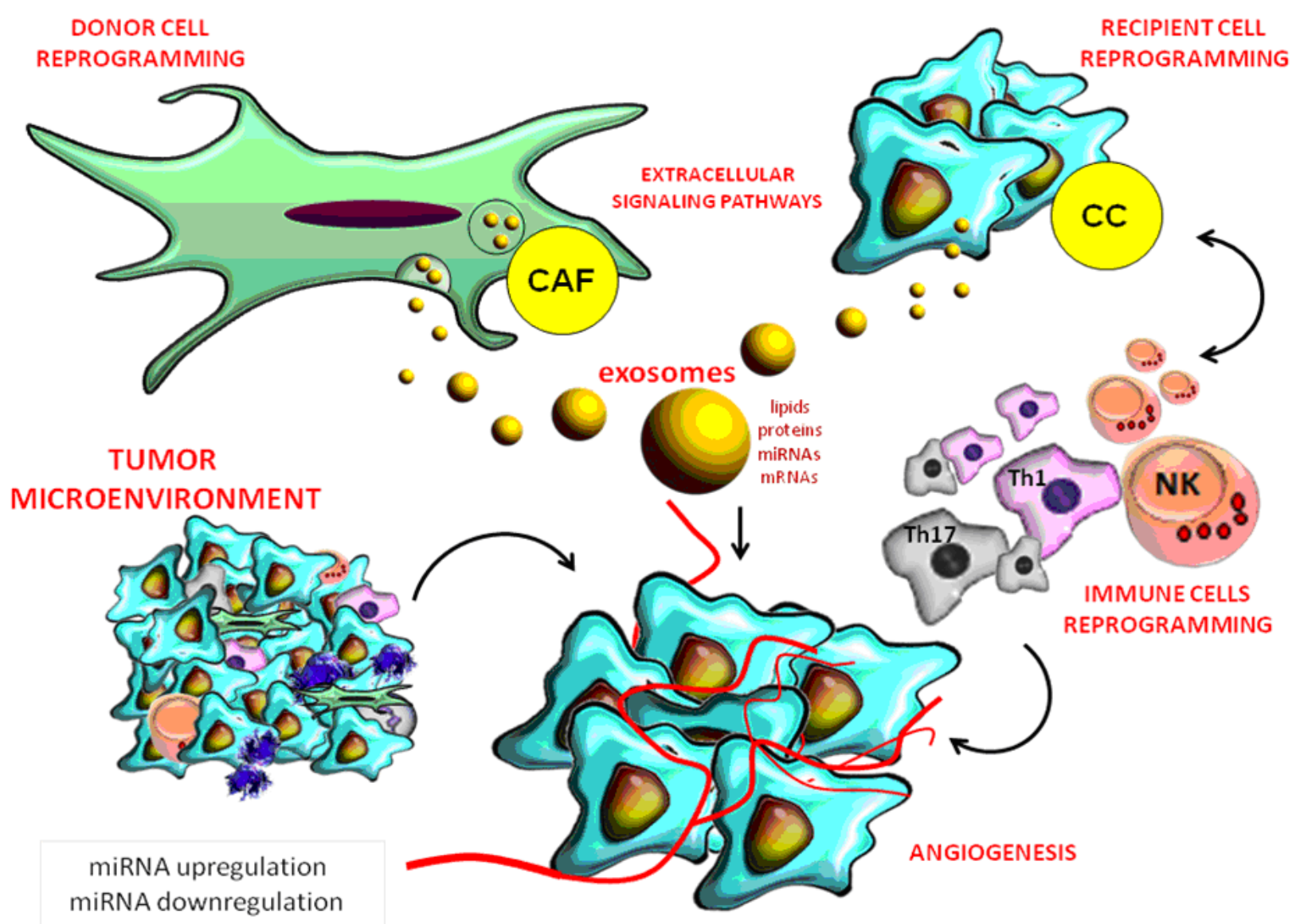

Figure 2: Role of miRNAs in the complex interactions between the tumor and stromal cells in its micro-environment. 
diagnosis, prognosis of liver disease, and therapy both as miRNA mimic and Antimir [28, 29].

In contrast, the up-regulation of miR-21 expression in HCC tissues promotes tumorigenesis as well as resistance to antitumor $5 \mathrm{FU}$ and interferon $\alpha$ combination therapy [30]. Moreover, serum $m i R-21$ serve as a diagnostic and prognostic biomarker in $C R C$ [31]. In contrast, miR-30a-3p was reported to also be downregulated in $\mathrm{HCC}$, acting as a tumor suppressor in vitro. In addition, miR-30a-5p acts as a tumor-suppressing miRNA in colon cancer cells by targeting DTL (denticleless protein homolog) and modulating the cell cycle [32].

Metastasis is responsible for the rapid progress and death by HCC. miR-100 down-regulation in HCC and CRC tissues was strongly associated with venous invasion, poorer cell differentiation and shorter recurrence-free survival (Figure 1). Conversely, the restoration of miR100 inhibits cell growth and invasion. It also induces apoptosis, which renders it a potential target for cancer therapy. miR- 100 directly blocked the expression of ras-related $\mathrm{C} 3$ botulinum toxin substrate 1 (Rac1) and isoprenylcysteine carboxyl methyltransferase (ICMT) and, in turn, suppressed matrix metallopeptidase 2
(MMP2) activation [33, 34]. miR-145- 5p expression was down-regulated in HCC and CRC tissues [35, 36]. The polycistronic miR-17-92 cluster was the first microRNA cluster described to be involved in liver tumorigenesis. The microRNAs encoded by this cluster were grouped based on seed sequences into four families: miR-92, miR17, miR-18 and miR-19 [37, 38]

There are some examples of microRNAs with an essential impact on angiogenesis and ECM remodeling. Equally, miR-155 has a pivotal role in modulating livercancer-associated mesenchymal stem cell (LC-MSCs), the invasion promoting effect being attenuated by a miR155 antagonist [39]. MiR-155/- mice were found to have a better activation of the transforming growth factor $\beta$ (TGF $\beta$ )/(intracellular proteins that transduce extracellular signals from TGF $\beta$ ligands to the nucleus where they activate downstream gene transcription (SMAD) signaling pathway, which was correlated with expanded tumorigenesis, although the anti- tumorigenic response is unclear as the limited pre-clinical data available remains controversial [40].

Another EMT- regulatory miRNA is miR-9, a novel prognostic biomarker for HCC which modulates

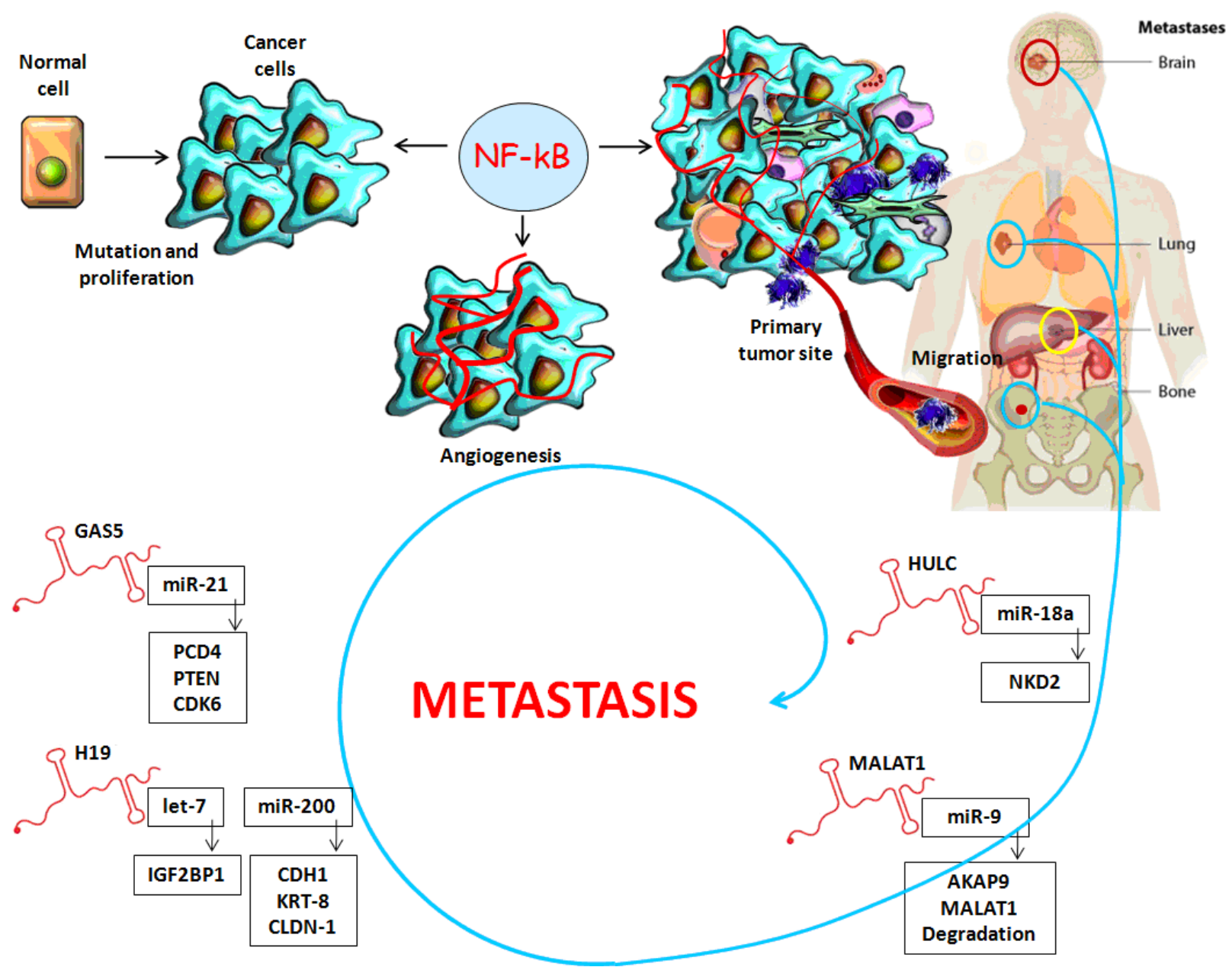

Figure 3: Long non-coding RNAs: A link between inflammatory microenvironment and cancer progression. 
Table 1: Examples of miRNAs associated with HCC and CRC

\begin{tabular}{|c|c|c|c|}
\hline miRNAs & Reported role in $\mathrm{HCC} / \mathrm{CRC}$ & Target genes & References \\
\hline miR- 26a & Anti-angiogenesis in $\mathrm{HCC}$ and anti-metabolic role in $\mathrm{CRC}$ & $\begin{array}{l}\text { HGF; cMet; EZH2, PTEN, SMAD1 } \\
\text { and MTDH }\end{array}$ & {$[22,23]$} \\
\hline miR-195 & Suppressor of $\mathrm{HCC} / \mathrm{CRC}$ angiogenesis and metastasis & Bcl-2; TNF- $\alpha$; NF-kB; cyclin D1 & {$[24,25]$} \\
\hline miR-126 & $\begin{array}{l}\text { Suppressor of angiogenesis and metastasis in } \mathrm{HCC} \text { and } \\
\text { CRC }\end{array}$ & $\begin{array}{l}\text { PISK, KRAS, EGFL7, CRK, } \\
\text { ADAM9, HOXA9, } \\
\text { IRS-1, SOX-2, SLC7A5 and VEGF }\end{array}$ & $\begin{array}{l}{[26,27} \\
106]\end{array}$ \\
\hline miR-122/a & $\begin{array}{l}\text { Liver homeostasis, hepatocarcinogenesis, down-regulated } \\
\text { in CRC }\end{array}$ & Klf6, Ctgf, IGF1R & {$[28,29]$} \\
\hline miR-21 & $\begin{array}{l}\text { Suppressor in CRC, liver tumorigenesis and resistance to } \\
\text { antitumor 5FU and interferon } \alpha \text { combination therapy; }\end{array}$ & $\begin{array}{l}\text { Pdcd4, PTEN, CDC25A, hMsh2 and } \\
\text { hMsh6 }\end{array}$ & {$[16,29,30]$} \\
\hline $\mathrm{miR}-30 \mathrm{a}-3 \mathrm{p} / 5 \mathrm{p}$ & $\begin{array}{l}\text { Inhibitor of tumor proliferation, invasiveness and } \\
\text { metastasis }\end{array}$ & AEG-1, DTL & {$[31,32]$} \\
\hline $\begin{array}{l}\text { miR-17- } 92, \quad \text { miR- } \\
106 b-25 \text { clusters }\end{array}$ & Oncogenic roles in hepatocellular carcinoma & c- Myc, PTEN & {$[37,38]$} \\
\hline miR-155 & HCC proliferation and metastasis & $\begin{array}{l}\text { SOX6, hMSH2, hMSH6, and } \\
\text { hMLH1, }\end{array}$ & {$[39,40]$} \\
\hline miR-9 & Angiogenesis in HCC. Tumorigenesis in CRC & E-cadherin & {$[41,42]$} \\
\hline miR-135b & HCC cell metastasis; CRC proliferation & HSF1, MSH2 & {$[44,45]$} \\
\hline miR-29b & Apoptosis promotion & Bcl-2 and Mcl-1, MMP-2 & {$[47,48]$} \\
\hline miR-142-3p & HCC and CRC proliferation & RAC1, CD 133, Lgr 5, ABCG2 & {$[60,62,107]$} \\
\hline miR-210 & HCC metastasis; overexpressed in CRC & VMP1, CPEB2 & {$[51,52]$} \\
\hline miR-181a & Oncogenic role in HCC; poor survival in patients with CRC & CDX2, GATA6, NLK, EGFR & {$[64,65]$} \\
\hline miR- 224 & Oncogenic role in $\mathrm{HCC}$; prognostic marker in CRC & SMAD4, API-5 & {$[49,63]$} \\
\hline
\end{tabular}

angiogenesis via vascular endothelial growth factor-A (VEGF-A). miR- 9 could function as a microtumor promoter gene in HCC because its up-regulation was significantly correlated with aggressive clinicopathological parameters [18, 41, 42]. The level of miR-9 was higher in tumor tissues with high Prospero homeobox 1 (PROX1) has been shown to promote CRC progression) /low E-cadherin (which has a key role in cell adhesion) than that of tumor tissues with low PROX1/high E- cadherin [43].

miR- 135b up-regulation in HCC tissues facilitates the generation of an IL-17- producing immunophenotype by interfering with the normal lymphocyte differentiation program. Additionally, the reversion-inducing-cysteinerich protein with kazal motifs (RECK) and ecotropic viral integration site 5 (EVI5) were identified as the functional and direct targets of miR-135b in HCC. Likewise, heat shock transcription factor 1 (HSF1) directly activates the miR-135b expression, consequently enhancing $\mathrm{HCC}$ invasiveness [44].

The miR-135b blockage in CRC experimental mouse models diminishes tumor evolution by suppressing the genes involved in proliferation, apoptosis and invasion. Recent research identified miR-135b as a key effector of oncogenic pathways and a promising target for CRC therapy [45]. The development of new therapeutics against HCC could be thus facilitated by the recently identified HSF 1/miR-135b/RECK\&EVI5 axis in the mechanisms of HCC metastasis [17; 44]. Additionally, it was shown that serum miRNA-210 could be a predictive biomarker for treatment response and prognosis in HCC patients [46].
In order to determine the role of miRs in a cell program, it was shown that miR-29b sensitizes HCC cells to apoptosis by directly targeting two anti-apoptotic molecules such as Bcl-2 and Mcl-1. Similarly, miR-29b deregulation is involved in CRC. The down-regulation of miR-29b enhances tumorigenesis and angiogenesis by affecting the endothelial cells. This effect is due to an increase in MMP-2 expression, which promotes VEGFR signaling in the endothelial cells $[47,48]$. miR- 224 also plays an oncogenic role in HCC tumor formation and hepatoma cell migration through silencing its target gene named SMAD Family Member $4(\operatorname{Smad} 4)[49]$.

Understanding the two-way communication between stroma and tumor is essential because extracellular miRNAs could inhibit tumor development and prognosis in the HCC microenvironment [18]. miR-122, miR-30a$3 p$, miR-145-5p and miR-29b are circulating miRNAs that may be used as non-invasive biomarkers for the detection of cancer. Moreover, the transfer of secretory exosomal miRNAs to a recipient cell may suppress target gene expression [50].

For instance, miR-210 and miR-155, which are overexpressed in HCC and CRC, promote the metastatic potential of $\mathrm{HCC}$ cells by targeting the vacuole membrane protein 1 (VMP1), in this way being an example of tumorto- stroma communication (Figure 1) [39, 50, 51, 52]. An example of tumor- stroma communication is provided by the S100A4-miR155-SOCS1-MMP9 axis. SOCS1 is a suppressor of liver fibrosis while protein S100A4 secreted from liver cancer-associated mesenchymal stem cells (LCMSCs) speeds up HCC cell proliferation and invasion thus 
Table 2: Similarities and differences between IncRNAS associated with CRC and HCC

\begin{tabular}{|c|c|c|c|c|c|c|c|}
\hline \multicolumn{4}{|c|}{ Commonly altered IncRNAs in CRC and HCC } & \multicolumn{4}{|c|}{ IncRNAs associated with HCC } \\
\hline IncRNA & Role & Target gene & References & IncRNA & Specific role & $\begin{array}{c}\text { Target } \\
\text { gene }\end{array}$ & References \\
\hline HULC & $\begin{array}{l}\text { High expression in } \mathrm{HCC} \\
\begin{array}{l}\text { correlated with tumor } \\
\text { grade }\end{array}\end{array}$ & NKD2 & $\begin{array}{l}{[70,72,73,} \\
108]\end{array}$ & IncRNA- MVIH & $\begin{array}{l}\text { Microvascular } \\
\text { invasion }\end{array}$ & $\mathrm{EZH} 2$ & {$[84,105]$} \\
\hline HOTAIR & $\begin{array}{llr}\begin{array}{l}\text { Correlated with } \\
\text { cell invasion }\end{array} & \text { and } \\
\text { chemosensitivity } & \\
\end{array}$ & $\begin{array}{l}\text { CDH1, } \\
\text { PRC2 }\end{array}$ & $\begin{array}{l}{\left[\begin{array}{l}69,70, \\
97,109]\end{array}\right.}\end{array}$ & IncRNA-LALR1 & Liver regeneration & $\begin{array}{l}\text { Cend1 } \\
\text { Wnt }\end{array}$ & {$[87]$} \\
\hline MALAT1 & $\begin{array}{l}\text { Associated with metastasis } \\
\text { and disease recurrence }\end{array}$ & AKAP-9 & {$[70,72]$} & IncRNA-RoR & $\begin{array}{|ll|}\begin{array}{l}\text { Modulation of } \\
\text { cellular response to } \\
\text { chemotherapy }\end{array} \\
\end{array}$ & EZH2 & {$[84]$} \\
\hline XIST & Microvascular invasion & BRCA1 & {$[67]$} & IncRNA-hPVT1 & \begin{tabular}{|l|} 
HCC growth \\
\end{tabular} & NOP2 & {$[30,86]$} \\
\hline H19 & $\begin{array}{l}\text { Highly expressed in } \mathrm{HCC} / \\
\text { CRC and peri-tumor area, } \\
\text { correlated with prognosis }\end{array}$ & \begin{tabular}{|l|} 
CDH1, \\
KRT-8, \\
KRT-19, \\
CLDN1, \\
RB \\
\end{tabular} & $\begin{array}{l}{[74,75,76,} \\
110]\end{array}$ & IncRNA-HEIH & Cell proliferation & $\mathrm{EZH} 2$ & {$[30]$} \\
\hline GAS5 & $\begin{array}{l}\text { Decreased in HCC } \\
\text { Significantly associated } \\
\text { with HCC-CRC prognosis } \\
\end{array}$ & $\begin{array}{l}\text { CDK6, p53 } \\
\text { E2F1 }\end{array}$ & $\begin{array}{l}{[70,79,91,81,} \\
83]\end{array}$ & $\begin{array}{l}\text { IncRNA- } \\
\text { PCNA-AS1 }\end{array}$ & HCC growth & $\begin{array}{l}\text { PCNA- } \\
\text { AS1 }\end{array}$ & {$[87,88]$} \\
\hline \multicolumn{4}{|c|}{ IncRNAs associated with CRC } & \multirow{2}{*}{ MEG3 } & \multirow{2}{*}{$\begin{array}{l}\text { HCC growth } \\
\text { control }\end{array}$} & \multirow{2}{*}{ p53 } & \multirow{2}{*}[87]{} \\
\hline IncRNA & Specific role & Target gene & References & & & & \\
\hline POU5F1P1 & Increased risk of CRC & Brg1 & {$[2]$} & $\begin{array}{l}\text { LncRNA- } \\
\text { DREH }\end{array}$ & \begin{tabular}{|l|}
$\begin{array}{l}\text { Inhibits growth and } \\
\text { metastasis }\end{array}$ \\
\end{tabular} & HBx & {$[87,88]$} \\
\hline PTENP1 & Growth- suppressive role & PTEN & {$[2]$} & LncRNA-LET & $\begin{array}{|lr|}\begin{array}{l}\text { Inhibits } \\
\text { induced } \\
\text { metastasis }\end{array} & \text { HCC } \\
\end{array}$ & $\begin{array}{l}\text { NF90, } \\
\text { HIF-1 } \alpha\end{array}$ & {$[87,90]$} \\
\hline MYLKP1 & $\begin{array}{l}\text { Increased } \\
\text { proliferation }\end{array}$ & smMLCK & {$[2]$} & LncRNA-ATB & \begin{tabular}{|l|} 
Promotes EMT, \\
HCC invasion and \\
metastasis
\end{tabular} & ZEB1 & {$[79,87,111]$} \\
\hline \multirow{2}{*}{ CCAT1 } & \multirow{2}{*}{$\begin{array}{l}\text { Cell proliferation and } \\
\text { invasion }\end{array}$} & \multirow{2}{*}{ MYC } & \multirow{2}{*}[2,98]{} & \multicolumn{4}{|c|}{ ucRNAs associated with HCC } \\
\hline & & & & ucRNA & Specific role & \begin{tabular}{|l} 
Target \\
gene
\end{tabular} & References \\
\hline CCAT2 & Tumor growth, metastasis & $\begin{array}{l}\text { MYC } \\
\text { WNT }\end{array}$ & {$[20]$} & $\begin{array}{l}\text { IncRNA- } \\
\text { TUC338 }\end{array}$ & HCC growth & TIMP-1 & {$[67]$} \\
\hline \multicolumn{4}{|c|}{ ucRNAs associated with CRC } & \multirow{2}{*}{$\begin{array}{l}\text { IncRNA- } \\
\text { TUC339 }\end{array}$} & \multirow{2}{*}{$\begin{array}{l}\text { HCC growth and } \\
\text { spread }\end{array}$} & \multirow{2}{*}{ NA } & \multirow{2}{*}{$\begin{array}{l}{[67, \quad 80,} \\
112]\end{array}$} \\
\hline ucRNA & Specific role & Target gene & References & & & & \\
\hline uc 73A & Oncogene & $\begin{array}{l}\text { caspase-3, } \\
\text { annexinV, } \\
\text { TP53 }\end{array}$ & {$[103,104]$} & uc001ncr & $\begin{array}{l}\text { High expression } \\
\text { in both tissues and } \\
\text { serum samples in } \\
\text { HBV-positive HCC }\end{array}$ & NA & {$[105]$} \\
\hline uc 388 & Metastasis & NA & {$[2]$} & AX800134 & $\begin{array}{l}\text { High expression } \\
\text { in both tissues and } \\
\text { serum samples in } \\
\text { HBV-positive HCC }\end{array}$ & NA & {$[105]$} \\
\hline
\end{tabular}

being involved in the modulation of HCC progression [53].

\section{EXOSOMAL MIRNAS}

HCC cells release extracellular micro vesicles, especially exosomes. These are natural carriers of intercellular communication of $50-90 \mathrm{~nm}$ in diameter released by all cells, including both cancer and tumor microenvironment cells, under certain physiological and pathological conditions [54].

Exosomes contain proteins, lipids and microRNAs and function as information carriers that control the function of target cells. Tumor stroma contains fibroblasts and exosomes that promote tumorigenesis and metastatic progression through cytokines, lipids, proteins, growth factors and non-coding RNAs (ncRNAs) by increasing the expression of matrix metalloproteinases (MMP) or by promoting angiogenesis $[1,55]$ (Figure 2). 
Examples of ncRNAs included in exosomes are: miRNAs and long non-coding RNA (lncRNA), which are powerful regulators of cell signaling pathways, small nuclear RNA (snRNA), small nucleolar RNA (snoRNA), long intergenic non-coding RNA (lincRNA), ribosomal RNA (rRNA), piwi-interacting RNA (piRNA), circular RNA (circ RNA) and transfer RNA (tRNA) [56, 57, 58].

Research demonstrated that like hormones, exosomal miRNAs secreted by a donor cell were taken up by a recipient cell and remained functional both in vivo and in vitro studies. On the one hand, the intravenous administration of B-cell derived exosomes loaded with miR-155 correlated with significantly increased miR-155 expression in the liver of miR-knockout mice compared with controls $[1,57,59]$. On the other hand, transiently transfected human embryonic kidney cells were used to set up exosomes loaded with let-7a, a crucial tumor suppressor miRNA that is down-regulated in breast cancer [1, 15, 54]. A stromal- to- tumor MVs- mediated transfer from macrophages to HCC cells transported miR-142-3p. More interestingly, a miR-142-3p inhibitor named Propofol blocked tumor growth in mice through macrophage activation, and also stimulated tumorassociated macrophages (TAMs) to produce MVs, which secreted miR-142-3p to HCC cells, resulting in the inhibition of HCC cell migration [60, 61].

miR-142-3p and miR-224 could be considered important predictive and prognostic markers in CRC and $\mathrm{HCC}$ as they are secreted in the circulatory system through exosomal compartments. miR-224 accelerates the $\mathrm{G}_{1} / \mathrm{S}$-phase transition through the activation of the protein kinase $\mathrm{B} /$ Forkhead box $\mathrm{O} 3$ transcription factor (Akt/FOXO3a) signaled by targeting antagonists of Phosphatidylinositol-3-Kinase (PI3K)/Akt such as the protein phosphatases PHLPP1 and PHLPP2. miR-224 also up-regulates cyclin-D1 and down-regulates cyclindependent kinase inhibitors such as p27Kip1 and p21Cip1. Therefore, miR-224 promotes CRC tumor growth and metastasis via targeting SMAD4. Alone or in combination with SMAD4, miR-224 could be an independent prognostic marker for the survival of CRC patients $[62,63$ ]. MVc contains miR-155, an oncogenic microRNA that is significantly up-regulated by coculture with LC-MSCs and by S100A4 ectopic overexpression [39] (Table 1).

miR- 200 family members seem to play a central role in EMT in both physiologic and malignant cells. They were released into exosomes thereby repressing the epithelial to mesenchymal transition by acting on the axis of the ZEB transcription factors. In addition, horizontal miR-200 signaling prevents the permeation of CRC cells into adjacent epithelia and contributes to organ integrity [64].

Recent studies demonstrated for the first time that c-Met is a miR-181a-5p functional target gene and that loss of miR-181a-5p expression leads to the activation of c-Met-mediated oncogenic signaling pathway in HCC. In this way, a novel molecular mechanism of c-Met regulation in HCC was highlighted and methods to increase miR181a5p level proved to support the inhibitory effects of c-Met blockers. miR-181a expression level is associated with poor survival in patients with CRC. Moreover, miR181 a expression might predict progression-free survival in epidermal growth factor receptor (EGFR) - targeted therapy in CRC patients [65] (Table 1).

\section{COMMON AND SPECIFIC LNCRNAS INVOLVED IN HCC AND CRC}

Similar to miRNAs, tissue expression levels of lncRNAs are deregulated in hepatocarcinogenesis and CRC where they target multiple signaling pathways. This indicates that they could serve as novel diagnostic and prognostic biomarkers in both types of cancer, as well as new replacement therapy without side effects for personalized treatment [61] (Table 2). In order to establish a more personalized therapy and a better prognosis, it is very important to create a novel HCC classification based on the lncRNAs signature, which is more specific in assessing the risk of tumor recurrence and prognosis after liver transplantation. For this purpose, the tissue expression of the following lncRNAs were used: the long non-coding RNA HOX-class I homebox genes-transcript antisense intergenic RNA (HOTAIR), metastasisassociated lung adenocarcinoma transcript 1 (MALAT1), lncRNA- high expression in HCC (HEIH), TUC338, TUC339, maternally expressed gene-3 12 (MEG3 12), anti-differentiation ncRNA (ANCR) and highly upregulated in liver cancer (HULC). As a result, patients with a low risk lncRNA signature had a significantly better prognosis [66, 67] (Figure 3).

The most studied lncRNA is probably HOTAIR that encodes 39 transcriptional factors initially described as major regulators of embryonic development [68]. HOTAIR proved to be highly expressed in breast cancer tissue and to have therapeutic implications in HCCs progression. It represses RNA binding motif protein 38 (RBM 38), which could be targeted by the $\mathrm{p} 53$ protein that induces cell cycle arrest in G1 (Figure 2) [30, 69]. In addition, inhibition of HOTAIR by siRNA represents an efficient therapy in HCC [70]. HOTAIR is a long intervening non-coding RNA (lincRNA) that associates with Polycomb Repressive Complex 2 (PRC2)while its overexpression is strongly correlated with low survival rates in liver and colon cancer patients [71].

HULC is a lncRNA functioning as an oncogene which is dramatically up-regulated in HCC liver tissue compared with normal tissue and can be used as a noninvasive plasma biomarker for HCC diagnosis and prognosis $[70,72,73]$ (Figure 3).

MALAT1 has an important function as an oncogene in HCC and CRC prognosis as it is associated with metastasis and disease recurrence. A vital anticancer 
therapy might be the silencing of MALAT1 activity through siRNA knockdown in order to decrease cell proliferation and invasion $[70,72,73]$ (Figure 3, Table 2).

Certain exosomes- enriched lncRNAs such as H19 and GAS5, which are overexpressed in HCC and CRC, could suppress cancer metastasis and cause epithelialmesenchymal transition (EMT). H19 alters the activation of miR-200 in cooperation with a specific protein complex [74]. Working together with miR-675, H19 promotes HCC invasion so that this type of lncRNA will be a therapeutic target and a potent diagnostic biomarker for hepatocarcinoma [75, 76]. H19 also promotes cell proliferation and cell-cycle progression in CRC by upregulating specific regulatory genes such as cyclin E1, D1 and Cyclin- dependent kinase 4 (CDK4) [77] (Figure 3; Table 2).

Growth arrest specific transcript 5 (GAS5) was significantly associated with HCC and CRC prognosis, it is used as a potential and independent biomarker for predicting clinical outcome [78, 79]. Otherwise, lncRNAGAS5 is a tumor suppressor associated with HCC and CRC clinical stage, tumor size and lymphnode metastasis [80]. GAS5 is a multi-functional lncRNA in CRC cells as it induces cell cycle arrest and tumor cell apoptosis by enhancing the G1 cell cycle through the cyclindependent kinase 6 (CDK6) pathway [81]. In HCC, the overexpression of GAS5 significantly promoted the apoptosis of hepatoma cells by negatively regulating the vimentin expression, a well-defined intermediate filament that has been linked to a more aggressive status in this tumor [82, 83] (Figure 3).

\section{Specific IncRNAs in HCC}

HCC- derived exosomes have selective enrichment of IncRNA, especially in lnc-RNA TUC339 and lncRNA regulator of reprogramming (ROR), which are involved in tumor cell reprogramming. These lncRNAs were demonstrated to modulate cellular responses to chemotherapy and target cell behavior thus offering promise for their potential as disease biomarkers [30, 84-85]. A high IncRNA-human plasmocytoma variant translocation 1 (hPVT1) expression is strongly associated with poor HCC prognosis [86, 87] (Table 2).

Another oncogenic lncRNA, HEIH is significantly associated with HCC evolution and works as an independent biomarker for predicting disease progression in HCC patients $[82,88]$. LncRNA- HEIH promotes proliferation in HCC and could be considered an independent prognostic factor for this type of cancer. Moreover, toxicity and other side effects may be reduced by replacement treatment with IncRNAs, which provides gene products that are normally present in unaltered tissues [30].

proliferating cell nuclear antigen antisense RNA1 (PCNA- AS1) promotes tumor cell growth and is highly up-regulated in this type of cancer while LncRNA-downregulated expression by hepatitis $\mathrm{B}$ virus $\mathrm{X}-\mathrm{HBX}$ - protein (DREH) is down-regulated especially in HBV-related HCC tissues and is also dramatically decreased in HCC patients with poor prognosis [89-91].

The expression of maternally expressed gene 3 (MEG3), which is down-regulated in HCC, may be regulated by microRNA-29. LncRNA- low expression in tumor (LET) is also down-regulated in HCC and contributes to hypoxia-mediated invasion. ATB- lncRNA activated by TGF- $\beta$ is highly expressed in HCC and strongly associated with poor prognosis in HCC patients $[87,90,91]$.

Therefore, the discovery of the impact of non-coding RNAs in HCC and CRC has led to useful applications in the clinical management of $\mathrm{HCC}$, future treatment being represented by a cocktail of T-cell modulators and vaccines enriched with the molecular targets of blockers in cancer-signaling pathways [68, 89; 92-97].

\section{Specific IncRNAs in CRC}

In contrast to miRNAs, which were largely studied for their roles in carcinogenesis, lncRNAs are less described. However, this review reveals the most specific non-coding RNAs in CRC and underlines their potential role in prevention and early detection [2] (Table 2).

c- Myc (a well-known transcription factor) activates the gene expression of lncRNA CRC-associated transcript 1 and 2 (CCAT1 and CCAT2), thus contributing to CRC tumorigenesis and metastasis. It is also a potential target for IncRNA direct therapy, being able to modify the clinical course of the disease $[98,99]$.

Pseudogenes of transcripts such as myosin light chain kinase pseudogene 1 (MYLKP1), octamer binding transcription factor 4 pseudogene 1 (POU5F1P1) and phosphatase and tensin homolog 1 pseudogene 1 (PTENP1) which target the tumor stroma in HCC are often deregulated in cancer tissues compared to normal cells. They are normally involved in CRC progression and significantly associated with survival time in the third stage of cancer [2].

\section{Small nucleolar RNAs (snoRNAs) in CRC and HCC}

SnoRNAs are a subclass of small non-coding RNAs (sncRNAs) (60 - $300 \mathrm{nt}$ ) involved in the adjustment of ribosomal RNAs (rRNAs) and transcribed by RNA polymerase II. Certain snoRNAs have different expressions in many human cancers including HCC and could serve as reference genes able to validate the expression of miRNAs [100-102].

This review focuses on studies verifying the association of snoRNAs with tumorigenesis in CRC. A positive correlation was established between p53 expression and snoRNAs concentrations derived from GAS5. At the same time, a significant correlation was 
found between miR-34a expression levels and both snoRNA U47 and snoRNA U44 [100].

\section{ULTRACONSERVED GENES (UCRNAS) IN HCC AND CRC}

Ultraconserved genes (UCGs) are another class of non-coding RNAs involved in CRC and HCC initiation and progression. They represent a special subset of mainly non-coding transcripts which are absolutely conserved during evolution and which can also regulate miRNAs by direct interaction. Fingerprints of differential UCG expression classify CRC and could be involved in metastasis [103] (Table 2).

Examples of the most important UCGs highly expressed in CRC include uc 29, uc 73, uc111, uc 112, uc 134, uc 206, uc 230, uc 292, uc 339, uc 34, uc 388 , uc 399 and uc 420. Furthermore, the intensity of uc 73 effects on survival and tumor cell proliferation in CRC corresponded to the degree of down-regulation by specific siRNAs. This UCG acts as an oncogene which raises the number of malignant cells as a result of reduced apoptosis rate in CRC cells [104].

HCC and CRC cell- derived exosomes contain ucRNAs and could be taken up by other HCC and CRC cells resulting in ucRNA intercellular transfer with consequent adjustment of cellular behavior [67]. Moreover, lncRNAs-UCGs represent potential targets of miRNAs while these complex regulatory mechanisms between UCGs and miRNAs may have prognostic significance for HCC and CRC patients [104].

LncRNA-TUC338 and LncRNA-TUC339 were also identified as two ucRNAs with an altered gene expression in HCC in order to activate modified cell growth in hepatocytes. However, TUC 339 is more enhanced within extracellular MVs released by hepatic cells than TUC 338, which has different functions. Therefore, the role of exosomes containing lncRNAs in intercellular communication and the transfer of constituents could be extended as biologically active signaling carriers. Moreover, the exosomes-mediated transfer of ucRNAs such as TUC339 represents a particular mechanism by which HCC cells modulate the microenvironment and encourage HCC growth [67, 82].

In addition, uc001ncr and AX800134 were selected as potential biomarkers in hepatitis B virus (HBV)positive $\mathrm{HCC}$ due to their significantly high-expression in both tissues and serum samples compared with controls, especially in early-stage disease or in patients with alphafetoprotein $($ AFP) $\leq 400 \mathrm{ng} / \mathrm{ml}[105]$.

\section{CONCLUDING REMARKS}

We have revealed common small non-coding RNA molecules (miR-26a, miR-195, miR- miR-126, miR122, miR-21, miR-155, miR-9, miR-135b, miR-29b,
miR-142-3p, miR-210, miR-181, miR- 224) in HCC and CRC, which suppress the expression of multiple genes involved in tumor- stromal interactions, immune invasion and tumor angiogenesis. Furthermore, we included their reported role and target genes in both types of cancer in a generic table (Table 1). We also highlighted common long non-coding RNA molecules such as HULC, HOTAIR, MALAT1, XIST, H19 and GAS5, which mediate the two-way interactions between stroma and tumor. These are overexpressed in CRC and HCC, thus causing EMT. They are also targeted by certain microRNAs with the cooperation of a specific protein complex. We also included all these long non-coding RNAs in a generic table (Table 2) and their mechanisms in the third figure of the manuscript.

CAFs are the predominant cell type in the stroma. They contribute to malignant transformation by stimulating the secretion of soluble factors such as the transforming growth factor- $\beta$ (TGF- $\beta$ ) or the hepatocyte growth factor. CAFs also secret fibroblast growth factor-2 (FGF-2) that activates angiogenesis and induces the metastatic capability and invasiveness of the cancer cells. Epithelial-mesenchymal transition (EMT) is a cellular program leading to cancer cell metastasis that is promoted by CAFs in both CRC and HCC. Exosomes containing microRNAs are secreted from both cancers and stromal cells and they suppress the gene expression of neighboring cells.

The tumor microenvironment (TME) is composed of fibroblasts, blood vessels, support cells, signaling molecules, immune cells and the extracellular matrix (ECM). Cancer cells (CC) grow in TME that favors tumor growth and contributes to therapy resistance. Major cell types in the tumor microenvironment are cancerassociated fibroblasts (CAFs), endothelial cells and immune cells, all of which communicate with cancer cells. One way that these cell types promote angiogenesis is by altering the expression of miRNAs either in associated normal cells or in cancer cells. Up-and down-regulation in miRNA expression can occur even through the direct communication between cells through exosomal miRNAs.

Chronic inflammation driven by the NF-kB signaling pathway is a critical component of cancer progression. The inflammatory microenvironment of tumor cells is a key participant in metastasis. In addition, tumor exosomes containing long non-coding RNAs, which are overexpressed in $\mathrm{HCC}$ and $\mathrm{CRC}$, are reliable players in the formation of the microenvironment by $\circ$ initiating the inflammatory process $\circ$ triggering angiogenesis $\circ$ enhancing the metastatic evolution of the primary tumor - preparing the "premetastatic niche," which dictates the pattern of metastatic spread in the new anatomical location. 


\section{Abbreviations}

HGF- Hepatocyte growth factor; cMet- HGFhepatocyte growth factor receptor; EZH2- Enhancer of zeste homolog 2; PTEN- phosphatase and tensin homolog; MTDH- Metadherin; NF-kB- nuclear factor kB; Bcl2- B-cell lymphoma/leukemia-2 gene; TNF- $\alpha$ - tumor necrosis factor- $\alpha$; PI3K- phosphatidylinositol 3-kinase; KRAS- Kristen-Rous sarcoma virus, EGFL7- epithelial growth factor (EGF)-like domain-containing protein 7, CRK- calcium-dependent protein kinase (CDPKs), CDPK-related kinases; ADAM9- A disintegrin and metalloproteinases; HOXA9- Homeobox A9; IRS-1- insulin-receptor substrate-1; SOX-2- Sry-type high-mobility-group box; SLC7A5- L-type amino acid transporters Lat1; VEGFvascular endothelial growth factor; Klf6- Kruppel-Like Factor 6; Ctgf- Connective Tissue Growth Factor; VEGFvascular endothelial growth factor; IGF1R- Insulin-like growth factor 1 receptor; Pdcd4- Programmed cell death 4; CDC25A- Cell division cycle 25A; hMsh2 and hMsh6human mutS homologue 2 and 6; AEG-1- astrocyte elevated gene 1; DTL- denticleless protein homolog; c- Myc- complete myelocytomatosis gene; SOX-6- sexdetermining region Y box 6; MSH2-MutS Homolog 2; HSF1- heat shock transcription factor 1; Mcl-1- Myeloid cell leukemia-1; MMP-2- matrix metalloproteinase-2; RAC1- recognition of Albugo candida; Lgr5-leucinerichrepeat G protein-coupled receptor 5; ABCG2- ATPBinding Cassette Transporter; VMP1- vacuole membrane protein 1; CPEB2- (cytoplasmic polyadenylation element binding protein 2; EGFR- epidermal growth factor receptor; CDX2- intestine-specific transcription factors; NLK- nemo-like kinase; API-5- apoptosis inhibitor-5; lncRNA - Long non-coding RNAs; HULC- highly upregulated in liver cancer; HOTAIR- HOX transcript antisense RNA; MALAT1- metastasis-associated lung adenocarcinoma transcript 1; HEIH- high expression in HCC; XIST- X-inactive specific transcript; GAS5- Growth arrest-specific transcript; NKD2- naked cuticle 2; CDH1E-cadherin-1; AKAP-9- PRKA kinase anchor protein 9; PRC2- polycomb repressive complex 2; KRT-8- keratin-8, KRT-19-keratin-19 and CLDN1- claudin 1, the markers for epithelial- to- mesenchymal transition; BRCA1- breast cancer 1 early onset; CDK6- cyclindependent kinase 6; E2F1- E2F transcription factor 1; MIF- macrophage migration inhibitory factor; CC- Cancer cells; MVIH - long non-coding RNA associated with microvascular invasion in HCC; LALR1- long non-coding RNA associated with liver regeneration 1; RoR- lincRNAregulator of reprogramming; MEG3- maternally expressed 3; hPVT1- human plasmocytoma variant translocation 1; PCNA-AS1- proliferating cell nuclear antigen antisense RNA1; DREH - down-regulated expression by HBx; LET - low expression in tumor; ATB- IncRNA activated by TGF- $\beta$; uc- (ultraconserved) RNAs; TUC338/339- HCC cell-derived extracellular vesicles cloned and identified as ucRNA; POU5F1P1- pseudogene, octamer binding transcription factor 4; MYLKP1- myosin light chain kinase pseudogene 1; PTENP1- phosphatase and tensin homolog 1 pseudogene 1; CCAT1/2- CRC-associated transcript; Akt/FOXO3a- protein kinase B/ Forkhead box O3 transcription factor; PI3K-Phosphatidylinositol3-Kinase; PHLPP1 and PHLPP2- protein phosphatases; p27Kip1 and p21Cip1-cyclin-dependent kinase inhibitors; TME- tumor micro-environment; HGF- hepatocyte growth factor; VEGFR2- vascular endothelial growth factor receptor 2; CAFs- cancer associated fibroblasts; Ccnd1cyclin D1; Wnt- wingless-type MMTV integration site family, member 1; NOP2- nucleolar protein 2; EZH2enhancer of zeste homolog 2; PCNA-AS1- proliferating cell nuclear antigen; $\mathrm{HBx}-$ Hepatitis $\mathrm{B}$ virus $\mathrm{X}$ protein; NF90- nuclear factor 90 protein; ZEB1- Zinc finger E-box binding homeobox 1; Brg1- brahma related gene-1 protein; RB- retinoblastoma protein; smMLCK- smooth muscle myosin light chain kinase; CCAT1, 2- colorectal cancer-associated transcript; TP53- tumor protein p53; TIMP-1- tissue inhibitor of metalloproteinases-1; NA- no data is available.

\section{ACKNOWLEDGMENTS AND FUNDING}

This paper was written as part of the research program "Partnerships in Priority Fields - PN II" supported by the Romanian Ministry of Education and the Executive Agency for Higher Education, Research, Development and Innovation Funding, project no. PN-IIPT-PCCA-2013-4-1959, contract no.193/2014.

\section{Author contributions}

Cătană CS initiated this review, searched the literature and contributed largely to the writing of the manuscript; Pichler M and Mader RM contributed with their own opinions to this review, surveyed and adviced the literature search, offered suggestions on the structure of this paper, contributed to the writing, reviewed all the versions of the manuscript and gave the final approval of the version to be published; Berindan Neagoe I and Giannelli G drafted the article and revised it critically for important intellectual content.

\section{CONFLICTS OF INTEREST}

The authors declare no conflict of interest.

\section{REFERENCES}

1. Ling H, Vincent K, Pichler M, Fodde R, Berindan-Neagoe I, Slack FJ, Călin GA. Junk DNA and the long non-coding RNA twist in cancer genetics. Oncogene. 2015; 34:5003- 
11.

2. Ye LC, Zhu X, Qiu JJ, Xu J, Wei Y. Involvement of long non-coding RNA in colorectal cancer: from benchtop to bedside (Review). Oncol Lett. 2015; 9:1039-45.

3. Pavlova NN, Thompson CB. The Emerging Hallmarks of Cancer Metabolism. Cell Metab. 2016; 23:27-47.

4. Torre LA, Bray F, Siegel RL, Ferlay J, Lortet-Tieulent J, Jemal A. Global cancer statistics, 2012. CA Cancer J Clin. 2015; 65:87-108. doi: 10.3322/caac.21262.

5. Global Burden of Disease Cancer Collaboration, Fitzmaurice C, Dicker D, Pain A, Hamavid H, MoradiLakeh M, MacIntyre MF, Allen C, Hansen G, Woodbrook R, Wolfe C, Hamadeh RR, Moore A, et al. The Global Burden of Cancer 2013. JAMA Oncol. 2015; 1:505-27. Erratum in: Errors in Author Names. [JAMA Oncol. 2015].

6. Barcena C, Stefanovic M, Tutusaus A, Martinez-Nieto GA, Martinez L, García-Ruiz C, de Mingo A, Caballeria J. Fernandez-Checa JC, Marí M, Morales A. Angiogenin secretion from hepatoma. Angiogenin secretion from hepatoma cells activates hepatic stellate cells to amplify a self-sustained cycle promoting liver cancer. Sci Rep. 2014; 5:e07916.

7. Bhome R, Al Saihati HA, Goh RW, Bullock MD, Primrose JN, Thomas GJ, Sayan AE, Mirnezami AH. Translational aspects in targeting the stromal tumour microenvironment: from bench to bedside. New Horiz Transl Med. 2016; 3:921.

8. Azzariti A, Mancarella S, Porcelli L, Quatrale AE, Caligiuri A, Lupo L, Dituri F, Giannelli G. Hepatic stellate cells induce hepatocellular carcinoma cell resistance to sorafenib through the laminin-332/ 33 integrin axis recovery of focal adhesion kinase ubiquitination. Hepatology. 2016; 64:2103-17.

9. Park SA, Kim MJ, Park SY, Kim JS, Lim W, Nam JS, Yhong Sheen Y. TIMP-1 mediates TGF- $\beta$-dependent crosstalk between hepatic stellate and cancer cells via FAK signaling. Sci Rep. 2015; 5:16492.

10. Coulouarn C, Clément B. Stellate cells and the development of liver cancer: therapeutic potential of targeting the stroma. J Hepatol. 2014; 60:1306-09.

11. Chen W, Lin H. Recent Advances in Identification of RNA Modifications Non-Coding RNA. 2017; 3:1.

12. Sheng J, Luo C, Jiang Y, Hinds PW, Xu Z, Hu GF. Transcription of angiogenin and ribonuclease 4 is regulated by RNA polymerase III elements and a CCCTC binding factor (CTCF)-dependent intragenic chromatin loop. J Biol Chem. 2014; 289:12520-34.

13. Braicu C, Cătană C, Călin GA, Berindan-Neagoe I. NCRNA combined therapy as future treatment option for cancer. Curr Pharm Des. 2014; 20:6565-74.

14. Otsuka M, Kishikawa T, Yoshikawa T, Ohno M, Takata A, Shibata C, Koike K. The role of microRNAs in hepatocarcinogenesis: current knowledge and future prospects. J Gastroenterol. 2014; 49:173-84.
15. Cătană CS, Călin GA, Berindan-Neagoe I. Inflamma-miRs in aging and breast cancer: are they reliable players? Front Med (Lausanne). 2015; 2:85.

16. Shibata C, Otsuka M, Kishikawa T, Ohno M, Yoshikawa T, Takata A, Koike K. Diagnostic and therapeutic application of noncoding RNAs for hepatocellular carcinoma. World J Hepatol. 2015; 7:1-6.

17. Gutschner T, Diederichs S. The hallmarks of cancer: a long non-coding RNA point of view. RNA Biol. 2012; 9:703-19.

18. Pichler M, Ress AL, Winter E, Stiegelbauer V, Karbiener M, Schwarzenbacher D, Scheideler M, Ivan C, Jahn SW, Kiesslich T, Gerger A, Bauernhofer T, Calin GA, Hoefler G. MiR-200a regulates epithelial to mesenchymal transition-related gene expression and determines prognosis in colorectal cancer patients. Br J Cancer. 2014; 110:161421.

19. Kuninty PR, Schnittert J, Storm G, Prakash J. MicroRNAs targeting to modulate tumor microenvironment. Front Oncol. 2016; 6:3.

20. Bullock MD, Silva AM, Kanlikilicer-Unaldi P, Filant J, Rashed M, Sood AK, Lopez-Berestein G, Calin GA. Exosomal Non-Coding RNAs: Diagnostic, Prognostic and Therapeutic Applications in Cancer. Non-Coding RNA. $2015 ; 1: 53-68$.

21. Le MT, Hamar P, Guo C, Basar E, Perdigão-Henriques R, Balaj L, Lieberman J. miR-200-containing extracellular vesicles promote breast cancer cell metastasis. J Clin Invest. 2014; 124:5109-28.

22. Yang X, Zhang XF, Lu X, Jia HL, Liang L, Dong QZ, Ye $\mathrm{QH}$, Qin LX. MicroRNA-26a suppresses angiogenesis in human hepatocellular carcinoma by targeting hepatocyte growth factor-cMet pathway. Hepatology. 2014; 59:187485.

23. Chen B, Liu Y, Jin X, Lu W, Liu J, Xia Z, Yuan Q, Zhao $\mathrm{X}, \mathrm{Xu} \mathrm{N}$, Liang $\mathrm{S}$. MicroRNA-26a regulates glucose metabolism by direct targeting PDHX in colorectal cancer cells. BMC Cancer. 2014; 14:443.

24. Wang R, Zhao N, Li S, Fang JH, Chen MX, Yang J, Jia WH, Yuan Y, Zhuang SM. MicroRNA-195 suppresses angiogenesis and metastasis of hepatocellular carcinoma by inhibiting the expression of VEGF, VAV2, and CDC42. Hepatology. 2013; 58:642-53.

25. Cai H, Zhao H, Tang J, Wu H. Serum miR-195 is a diagnostic and prognostic marker for osteosarcoma. J Surg Res. 2015; 194:505-10.

26. Du C, Lv Z, Cao L, Ding C, Gyabaah OA, Xie H, Zhou L, Wu J, Zheng S. MiR-126-3p suppresses tumor metastasis and angiogenesis of hepatocellular carcinoma by targeting LRP6 and PIK3R2. J Transl Med. 2014; 12:259.

27. Huang W, Lin J, Zhang H. miR-126: A novel regulator in colon cancer. Biomed Rep. 2016; 4:131-34.

28. Thakral S, Ghoshal K. miR-122 is a unique molecule with great potential in diagnosis, prognosis of liver disease, and therapy both as miRNA mimic and antimir. Curr Gene 
Ther. 2015; 15:142-50.

29. Wang H, Cao F, Li X, Miao H, e J, Xing J, Fu CG. miR320b suppresses cell proliferation by targeting c-Myc in human colorectal cancer cells. BMC Cancer. 2015; 15:748.

30. Li C, Chen J, Zhang K, Feng B, Wang R, Chen L. Progress and Prospects of Long Noncoding RNAs (lncRNAs) in Hepatocellular Carcinoma. Cell Physiol Biochem. 2015; $36: 423-34$.

31. Wang W, Lin H, Zhou L, Zhu Q, Gao S, Xie H, Liu Z, Xu Z, Wei J, Huang X, Zheng S. MicroRNA-30a-3p inhibits tumor proliferation, invasiveness and metastasis and is downregulated in hepatocellular carcinoma. Eur J Surg Oncol. 2014; 40:1586-94.

32. Baraniskin A, Birkenkamp-Demtroder K, Maghnouj A, Zöllner H, Munding J, Klein-Scory S, Reinacher-Schick A, Schwarte-Waldhoff I, Schmiegel W, Hahn SA. MiR-30a-5p suppresses tumor growth in colon carcinoma by targeting DTL. Carcinogenesis. 2012; 33:732-39.

33. Zhou HC, Fang JH, Luo X, Zhang L, Yang J, Zhang C, Zhuang SM. Downregulation of microRNA-100 enhances the ICMT-Rac1 signaling and promotes metastasis of hepatocellular carcinoma cells. Oncotarget. 2014; 5:1217788. doi: 10.18632/oncotarget.2601.

34. Qin C, Huang RY, Wang ZX. Potential role of miR-100 in cancer diagnosis, prognosis, and therapy. Tumour Biol. 2015; 36:1403-09.

35. Shi KQ, Lin Z, Chen XJ, Song M, Wang YQ, Cai YJ, Yang NB, Zheng MH, Dong JZ, Zhang L, Chen YP. Hepatocellular carcinoma associated microRNA expression signature: integrated bioinformatics analysis, experimental validation and clinical significance. Oncotarget. 2015; 6:25093-108. doi: 10.18632/oncotarget.4437.

36. Chen X, Shi K, Wang Y, Song M, Zhou W, Tu H, Lin Z. Clinical value of integrated-signature miRNAs in colorectal cancer: miRNA expression profiling analysis and experimental validation. Oncotarget. 2015; 6:37544-56. doi: 10.18632/oncotarget.6065.

37. Tan W, Li Y, Lim SG, Tan TM. miR-106b-25/miR-17-92 clusters: polycistrons with oncogenic roles in hepatocellular carcinoma. World J Gastroenterol. 2014; 20:5962-72.

38. Meng WJ, Yang L, Ma Q, Zhang H, Adell G, Arbman G, Wang ZQ, Li Y, Zhou ZG, Sun XF. MicroRNA Expression Profile Reveals miR-17-92 and miR-143-145 Cluster in Synchronous Colorectal Cancer. Medicine (Baltimore). 2015; 94:e1297.

39. Yan XL, Jia YL, Chen L, Zeng Q, Zhou JN, Fu CJ, Chen HX, Yuan HF, Li ZW, Shi L, Xu YC, Wang JX, Zhang XM, et al. Hepatocellular carcinoma-associated mesenchymal stem cells promote hepatocarcinoma progression: role of the S100A4-miR155-SOCS1-MMP9 axis. Hepatology. 2013; 57:2274-86.

40. Velázquez KT, Enos RT, McClellan JL, Cranford TL, Chatzistamou I, Singh UP, Nagarkatti M, Nagarkatti PS, Fan D, Murphy EA. MicroRNA-155 deletion promotes tumorigenesis in the azoxymethane-dextran sulfate sodium model of colon cancer. Am J Physiol Gastrointest Liver Physiol. 2016; 310:G347-58.

41. Cai L, Cai X. Up-regulation of miR-9 expression predicate advanced clinicopathological features and poor prognosis in patients with hepatocellular carcinoma. Diagn Pathol. 2014; 9:1000.

42. Chen X, Zhu L, Ma Z, Sun G, Luo X, Li M, Zhai S, Li P, Wang X. Oncogenic miR-9 is a target of erlotinib in NSCLCs. Sci Rep. 2015; 5:17031.

43. Lu MH, Huang CC, Pan MR, Chen HH, Hung WC. Prospero homeobox 1 promotes epithelial-mesenchymal transition in colon cancer cells by inhibiting E-cadherin via miR-9. Clin Cancer Res. 2012; 18:6416-25.

44. Li Y, Xu D, Bao C, Zhang Y, Chen D, Zhao F, Ding J, Liang L, Wang Q, Liu L, Li J, Yao M, Huang S, et al. MicroRNA-135b, a HSF1 target, promotes tumor invasion and metastasis by regulating RECK and EVI5 in hepatocellular carcinoma. Oncotarget. 2015; 6:2421-33. doi: 10.18632/oncotarget.2965.

45. Valeri N, Braconi C, Gasparini P, Murgia C, Lampis A, Paulus-Hock V, Hart JR, Ueno L, Grivennikov SI, Lovat F, Paone A, Cascione L, Sumani KM, et al. MicroRNA-135b promotes cancer progression by acting as a downstream effector of oncogenic pathways in colon cancer. Cancer Cell. 2014; 25:469-83.

46. Zhan M, Li Y, Hu B, He X, Huang J, Zhao Y, Fu S, Lu L. Serum microRNA-210 as a predictive biomarker for treatment response and prognosis in patients with hepatocellular carcinoma undergoing transarterial chemoembolization. J Vasc Interv Radiol. 2014; 25:12791287.e1.

47. Yan B, Guo Q, Fu FJ, Wang Z, Yin Z, Wei YB, Yang JR. The role of miR-29b in cancer: regulation, function, and signaling. Onco Targets Ther. 2015; 8:539-48.

48. Wojcik SE, Rossi S, Shimizu M, Nicoloso MS, Cimmino A, Alder H, Herlea V, Rassenti LZ, Rai KR, Kipps TJ, Keating MJ, Croce CM, Calin GA. Non-codingRNA sequence variations in human chronic lymphocytic leukemia and colorectal cancer. Carcinogenesis. 2010; 31:208-15.

49. Lan SH, Wu SY, Zuchini R, Lin XZ, Su IJ, Tsai TF, Lin YJ, Wu CT, Liu HS. Autophagy suppresses tumorigenesis of hepatitis B virus-associated hepatocellular carcinoma through degradation of microRNA-224. Hepatology. 2014; 59:505-17.

50. Kanlikilicer P, Rashed MH, Bayraktar R, Mitra R, Ivan C, Aslan B, Zhang X, Filant J, Silva AM, Rodriguez-Aguayo C, Bayraktar E, Pichler M, Ozpolat B, et al. Ubiquitous release of exosomal tumor suppressor miR-6126 from ovarian cancer cells. Cancer Res. 2016; 76:7194-207.

51. Ying Q, Liang L, Guo W, Zha R, Tian Q, Huang S, Yao J, Ding J, Bao M, Ge C, Yao M, Li J, He X. Hypoxiainducible microRNA-210 augments the metastatic potential of tumor cells by targeting vacuole membrane protein 1 in hepatocellular carcinoma. Hepatology. 2011; 54:2064-75. 
52. Kawaguchi T, Komatsu S, Ichikawa D, Morimura R, Tsujiura M, Konishi H, Takeshita H, Nagata H, Arita T, Hirajima S, Shiozaki A, Ikoma H, Okamoto K, et al. Clinical impact of circulating miR-221 in plasma of patients with pancreatic cancer. Br J Cancer. 2013; 108:361-69.

53. Afonso MB, Rodrigues $\mathrm{PM}$, Simão $\mathrm{AL}$, Castro RE. Circulating microRNAs as Potential Biomarkers in Non-Alcoholic Fatty Liver Disease and Hepatocellular Carcinoma. J Clin Med. 2016; 5:30.

54. Neviani P, Fabbri M. Exosomic microRNAs in the Tumor Microenvironment. Front Med (Lausanne). 2015; 2:47.

55. Lemoinne S, Thabut D, Housset C, Moreau R, Valla D, Boulanger CM, Rautou PE. The emerging roles of microvesicles in liver diseases. Nat Rev Gastroenterol Hepatol. 2014; 11:350-61.

56. Braicu C, Tomuleasa C, Monroig P, Cucuianu A, BerindanNeagoe I, Calin GA. Exosomes as divine messengers: are they the Hermes of modern molecular oncology? Cell Death Differ. 2015; 22:34-45.

57. Berindan-Neagoe I, Calin GA. Molecular pathways: microRNAs, cancer cells, and microenvironment. Clin Cancer Res. 2014; 20:6247-53.

58. Cheng L, Sun X, Scicluna BJ, Coleman BM, Hill AF. Characterization and deep sequencing analysis of exosomal and non-exosomal miRNA in human urine. Kidney Int. 2014; 86:433-44.

59. Momen-Heravi F, Bala S, Bukong T, Szabo G. Exosomemediated delivery of functionally active miRNA-155 inhibitor to macrophages. Nanomedicine (Lond). 2014; 10:1517-27.

60. Zhang J, Shan WF, Jin TT, Wu GQ, Xiong XX, Jin HY, Zhu SM. Propofol exerts anti-hepatocellular carcinoma by microvesicle-mediated transfer of miR-142-3p from macrophage to cancer cells. J Transl Med. 2014; 12:279.

61. Henry JC, Azevedo-Pouly AC, Schmittgen TD. MicroRNA replacement therapy for cancer. Pharm Res. 2011; 28:303042.

62. Dong $\mathrm{Y}, \mathrm{Wu} \mathrm{WK}, \mathrm{Wu} \mathrm{CW}$, Sung JJ, Yu J, Ng SS. MicroRNA dysregulation in colorectal cancer: a clinical perspective. Br J Cancer. 2011; 104:893-98.

63. Ling H, Pickard K, Ivan C, Isella C, Ikuo M, Mitter R, Spizzo R, Bullock MD, Braicu C, Pileczki V, Vincent K, Pichler M, Stiegelbauer V, et al. The clinical and biological significance of MIR-224 expression in colorectal cancer metastasis. Gut. 2016; 65:977-89.

64. Senfter D, Holzner S, Kalipciyan M, Staribacher A, Walzl A, Huttary N, Krieger S, Brenner S, Jäger W, Krupitza G, Dolznig H, Mader RM. Loss of miR-200 family in 5-fluorouracil resistant colon cancer drives lymphendothelial invasiveness in vitro. Hum Mol Genet. 2015; 24:3689-98.

65. Pichler M, Winter E, Ress AL, Bauernhofer T, Gerger A, Kiesslich T, Lax S, Samonigg H, Hoefler G. miR-181a is associated with poor clinical outcome in patients with colorectal cancer treated with EGFR inhibitor. J Clin Pathol. 2014; 67:198-203.

66. Yang Z, Ding C, Zheng S. A Novel Classification Of Hepatocellular Carcinoma Based On Long Noncoding RNA Signature: Implications For Prognosis. J Am Coll Surg. 2014; 219:S23.

67. Kogure T, Yan IK, Lin WL, Patel T. Extracellular VesicleMediated Transfer of a Novel Long Noncoding RNA TUC339: A Mechanism of Intercellular Signaling in Human Hepatocellular Cancer. Genes Cancer. 2013; 4:261-72. doi: 10.1177/1947601913499020.

68. Graham A, Papalopulu N, Krumlauf R. The murine and Drosophila homeobox gene complexes have common features of organization and expression. Cell. 1989; $57: 367-78$.

69. Gupta RA, Shah N, Wang KC, Kim J, Horlings HM, Wong DJ, Tsai MC, Hung T, Argani P, Rinn JL, Wang Y, Brzoska P, Kong B, et al. Long non-coding RNA HOTAIR reprograms chromatin state to promote cancer metastasis. Nature. 2010; 464:1071-76.

70. Panzitt K, Tschernatsch MM, Guelly C, Moustafa T, Stradner M, Strohmaier HM, Buck CR, Denk H, Schroeder R, Trauner M, Zatloukal K. Characterization of HULC, a novel gene with striking up-regulation in hepatocellular carcinoma, as noncoding RNA. Gastroenterology. 2007; 132:330-42.

71. Kim K, Jutooru I, Chadalapaka G, Johnson G, Frank J, Burghardt R, Kim S, Safe S. HOTAIR is a negative prognostic factor and exhibits pro-oncogenic activity in pancreatic cancer. Oncogene. 2013; 32:1616-25.

72. Quagliata L, Terracciano LM. Liver Diseases and Long Non-Coding RNAs: New Insight and Perspective. Front Med (Lausanne). 2014; 1:35.

73. Liz J, Esteller M. lncRNAs and microRNAs with a role in cancer development. Biochim Biophys Acta. 2016; 1859:169-76.

74. Ohtsuka M, Ling H, Ivan C, Pichler M, Matsushita D, Goblirsch M, Stiegelbauer V, Shigeyasu K, Zhang X, Chen M, Vidhu F, Bartholomeusz GA, Toiyama Y, et al. H19 Noncoding RNA, an Independent Prognostic Factor, Regulates Essential Rb-E2F and CDK8- $\beta$-Catenin Signaling in Colorectal Cancer. EBioMedicine. 2016; 13:113-24.

75. Xie H, Ma H, Zhou D. Plasma HULC as a promising novel biomarker for the detection of hepatocellular carcinoma. Biomed Res Int. 2013; 2013:136106.

76. Liang WC, Fu WM, Wong CW, Wang Y, Wang WM, Hu GX, Zhang L, Xiao LJ, Wan DC, Zhang JF, Waye MM. The lncRNA H19 promotes epithelial to mesenchymal transition by functioning as miRNA sponges in colorectal cancer. Oncotarget. 2015; 6:22513-25. doi: 10.18632/ oncotarget. 4154.

77. Han D, Gao X, Wang M, Qiao Y, Xu Y, Yang J, Dong N, He J, Sun Q, Lv G, Xu C, Tao J, Ma N. Long noncoding RNA H19 indicates a poor prognosis of colorectal cancer 
and promotes tumor growth by recruiting and binding to eIF4A3. Oncotarget. 2016; 7:22159-73. doi: 10.18632/ oncotarget.8063.

78. Li Y, Wang X. Role of long noncoding RNAs in malignant disease (Review). Mol Med Rep. 2016; 13:1463-69.

79. Saus E, Brunet-Vega A, Iraola-Guzmán S, Pegueroles C, Gabaldón T, Pericay C. Long Non-Coding RNAs As Potential Novel Prognostic Biomarkers in Colorectal Cancer. Front Genet. 2016; 7:54.

80. Tu ZQ, Li RJ, Mei JZ, Li XH. Down-regulation of long non-coding RNA GAS5 is associated with the prognosis of hepatocellular carcinoma. Int J Clin Exp Pathol. 2014; 7:4303-09.

81. Lei Y, Jing-jing L, Ke-nan Z, Qing-zhong T, Jin L. Ke-nan Z, Qing-zhong T and Jin L. A tumor suppressive role of lncRNA GAS5 in human colorectal cancer. Open Life Sci. 2016; 11:105-09.

82. Chang L, Li C, Lan T, Wu L, Yuan Y, Liu Q, Liu Z. Decreased expression of long non-coding RNA GAS5 indicates a poor prognosis and promotes cell proliferation and invasion in hepatocellular carcinoma by regulating vimentin. Mol Med Rep. 2016; 13:1541-50.

83. Ma C, Shi X, Zhu Q, Li Q, Liu Y, Yao Y, Song Y. The growth arrest-specific transcript 5 (GAS5): a pivotal tumor suppressor long noncoding RNA in human cancers. Tumour Biol. 2016; 37:1437-44.

84. Takahashi K, Yan I, Haga H, Patel T. Long noncoding RNA in liver diseases. Hepatology. 2014; 60:744-53.

85. Hewson C, Morris KV. Form and Function of ExosomeAssociated Long Non-coding RNAs in Cancer. Curr Top Microbiol Immunol. 2016; 394:41-56.

86. Wang F, Yuan JH, Wang SB, Yang F, Yuan SX, Ye C, Yang N, Zhou WP, Li WL, Li W, Sun SH. Oncofetal long noncoding RNA PVT1 promotes proliferation and stem cell-like property of hepatocellular carcinoma cells by stabilizing NOP2. Hepatology. 2014; 60:1278-90.

87. Sun J, Bie B, Zhang S, Yang J, Li Z. Long non-coding RNAs: critical players in hepatocellular carcinoma. Int $\mathrm{J}$ Mol Sci. 2014; 15:20434-48.

88. Yuan SX, Tao QF, Wang J, Yang F, Liu L, Wang LL, Zhang J, Yang Y, Liu H, Wang F, Sun SH, Zhou WP. Antisense long non-coding RNA PCNA-AS1 promotes tumor growth by regulating proliferating cell nuclear antigen in hepatocellular carcinoma. Cancer Lett. 2014; 349:87-94.

89. Huang JF, Guo YJ, Zhao CX, Yuan SX, Wang Y, Tang GN, Zhou WP, Sun SH. Hepatitis B virus X protein (HBx)related long noncoding RNA (lncRNA) down-regulated expression by HBx (Dreh) inhibits hepatocellular carcinoma metastasis by targeting the intermediate filament protein vimentin. Hepatology. 2013; 57:1882-92.

90. Yang F, Huo XS, Yuan SX, Zhang L, Zhou WP, Wang F, Sun SH. Repression of the long noncoding RNA-LET by histone deacetylase 3 contributes to hypoxia-mediated metastasis. Mol Cell. 2013; 49:1083-96.

91. Yuan JH, Yang F, Wang F, Ma JZ, Guo YJ, Tao QF, Liu F, Pan W, Wang TT, Zhou CC, Wang SB, Wang YZ, Yang $\mathrm{Y}$, et al. A long noncoding RNA activated by TGF- $\beta$ promotes the invasion-metastasis cascade in hepatocellular carcinoma. Cancer Cell. 2014; 25:666-81.

92. Abou-Alfa GK. Sorafenib use in hepatocellular carcinoma: more questions than answers. Hepatology. 2014; 60:15-18.

93. Arizumi T, Ueshima K, Takeda H, Osaki Y, Takita M, Inoue T, Kitai S, Yada N, Hagiwara S, Minami Y, Sakurai T, Nishida N, Kudo M. Comparison of systems for assessment of post-therapeutic response to sorafenib for hepatocellular carcinoma. J Gastroenterol. 2014; 49:157887.

94. Bertino G, Di Carlo I, Ardiri A, Calvagno GS, Demma S, Malaguarnera G, Bertino N, Malaguarnera M, Toro A, Malaguarnera M. Systemic therapies in hepatocellular carcinoma: present and future. Future Oncol. 2013; 9:153348.

95. Bertino G, Demma S, Bertino N, Ardiri A. Management of hepatocellular carcinoma: an update at the start of 2014. J Gastrointest Dig Syst. 2014; 4:178.

96. Bertino G, Demma S, Ardiri A, Proiti M, Gruttadauria S, Toro A, Malaguarnera G, Bertino N, Malaguarnera M, Malaguarnera M, Di Carlo I. Hepatocellular carcinoma: novel molecular targets in carcinogenesis for future therapies. Biomed Res Int. 2014; 2014:203693.

97. Zhang K, Sun X, Zhou X, Han L, Chen L, Shi Z, Zhang A, Ye M, Wang Q, Liu C, Wei J, Ren Y, Yang $\mathrm{J}$, et al. Long non-coding RNA HOTAIR promotes glioblastoma cell cycle progression in an EZH2 dependent manner. Oncotarget. 2015; 6:537-46. doi: 10.18632/ oncotarget.2681.

98. He X, Tan X, Wang X, Jin H, Liu L, Ma L, Yu H, Fan Z. C-Myc-activated long noncoding RNA CCAT1 promotes colon cancer cell proliferation and invasion. Tumour Biol. 2014; 35:12181-88.

99. Ling H, Spizzo R, Atlasi Y, Nicoloso M, Shimizu M, Redis RS, Nishida N, Gafà R, Song J, Guo Z, Ivan C, Barbarotto E, De Vries I, et al. CCAT2, a novel noncoding RNA mapping to $8 \mathrm{q} 24$, underlies metastatic progression and chromosomal instability in colon cancer. Genome Res. 2013; 23:1446-61.

100. Wang J, Song YX, Ma B, Wang JJ, Sun JX, Chen XW, Zhao JH, Yang YC, Wang ZN. Regulatory Roles of NonCoding RNAs in Colorectal Cancer. Int J Mol Sci. 2015; 16:19886-919.

101. Xu G, Yang F, Ding CL, Zhao LJ, Ren H, Zhao P, Wang W, Qi ZT. Small nucleolar RNA 113-1 suppresses tumorigenesis in hepatocellular carcinoma. Mol Cancer. 2014; 13:216.

102. Thorenoor N, Slaby O. Small nucleolar RNAs functioning and potential roles in cancer. Tumour Biol. 2015; 36:41-53.

103. Liz J, Portela A, Soler M, Gómez A, Ling H, Michlewski 
G, Calin GA, Guil S, Esteller M. Regulation of pri-miRNA processing by a long noncoding RNA transcribed from an ultraconserved region. Mol Cell. 2014; 55:138-47.

104. Călin GA, Liu CG, Ferracin M, Hyslop T, Spizzo R, Sevignani C, Fabbri M, Cimmino A, Lee EJ, Wojcik SE, Shimizu M, Tili E, Rossi S, et al. Ultraconserved regions encoding ncRNAs are altered in human leukemias and carcinomas. Cancer Cell. 2007; 12:215-29.

105. Wang K, Guo WX, Li N, Gao CF, Shi J, Tang YF, Shen F, Wu MC, Liu SR, Cheng SQ. Serum LncRNAs Profiles Serve as Novel Potential Biomarkers for the Diagnosis of HBV-Positive Hepatocellular Carcinoma. PLoS One. 2015; 10:e0144934.

106. Ebrahimi F, Gopalan V, Smith RA, Lam AK. miR-126 in human cancers: clinical roles and current perspectives. Exp Mol Pathol. 2014; 96:98-107.

107. Shen WW, Zeng Z, Zhu WX, Fu GH. MiR-142-3p functions as a tumor suppressor by targeting CD133, ABCG2, and Lgr5 in colon cancer cells. J Mol Med (Berl). 2013; 91:9891000.

108. Yang XJ, Huang CQ, Peng CW, Hou JX, Liu JY. Long noncoding RNA HULC promotes colorectal carcinoma progression through epigenetically repressing NKD2 expression. Gene. 2016; 592:172-78.

109. Yao Y, Li J, Wang L. Large intervening non-coding RNA HOTAIR is an indicator of poor prognosis and a therapeutic target in human cancers. Int J Mol Sci. 2014; 15:18985-99.

110. Smolle M, Uranitsch S, Gerger A, Pichler M, Haybaeck J. Current status of long non-coding RNAs in human cancer with specific focus on colorectal cancer. Int J Mol Sci. 2014; 15:13993-4013.

111. Huang D, Fang J, Luo G. Roles of long noncoding RNAs in Hepatocellular Carcinoma. Open Life Sci. 2016; 11:91-97.

112. Hewson C, Capraro D, Burdach J, Whitaker N, Morris KV. Extracellular vesicle associated long non-coding RNAs functionally enhance cell viability. Noncoding RNA Res. 2016; 1:3-11. 